\title{
Are Medical Students Able and Willing to Edit Wikipedia to Learn Components of Evidence-Based Practice?
}

\author{
Robert G. Badgett, M.D. ${ }^{1}$, Mary Moore, Ph.D. ${ }^{2}$ \\ ${ }^{1}$ University of Kansas School of Medicine-Wichita \\ Department of Internal Medicine \\ ${ }^{2}$ University of Miami Miller School of Medicine \\ Department of Health Informatics \\ Miami, FL
}

\begin{abstract}
Objective. This study sought to measure the ability and receptiveness of medical students for creating evidence-based edits in Wikipedia for learning components of evidence-based practice.

Methods. Senior medical school students in an elective in clinical informatics and evidencebased medicine during $2007(n=21)$ or $2008(n=18)$ were taught how to place succinct summaries of studies in Wikipedia. Online help was provided. In 2008, an online template facilitated editing.

Results. Combining the two years, all students but one (97\%) cited articles in PubMed and 85\% created links to abstracts in PubMed. Most students (79\%) reported a study design and 72\% provided numeric results. In $2007,14 \%$ of students created complete citations, compared to $78 \%$ in the second year $(\mathrm{p}<0.05)$. At two months follow-up, $44 \%$ of students had at least one edit improved and one edit from 2007 was deleted. In 2007, 83\% (15/18) of the students agreed or strongly agreed that the exercise should be offered to the next year's class. In 2008, this rate was $100 \%$ (16 respondents).

Conclusions. Among these self-selected students, most students were positive about the assignment and almost all created edits that succinctly summarized research results and attributed evidence.
\end{abstract}

KJM 2011; 4(3):62-69.

\section{Introduction}

Many physicians have difficulty reading and interpreting medical research. ${ }^{1-3}$ More specifically, physicians have difficulty interpreting probabilistic results, ${ }^{4-6}$ may overgeneralize findings to incorrect populations, $^{7-9}$ and may carry details incorrectly from studies into clinical practice. $^{3,7,8,10,11}$ Adverse clinical outcomes have been documented that may arise from these difficulties in interpreting and applying research evidence. ${ }^{8,9}$ In summary, when physicians try to answer questions, they are almost as likely to make an incorrect conclusion as a correct conclusion. $^{12}$ This may place physicians in the "position of knowing less than has been proved". 13

Teaching evidence-based practice and critical appraisal is challenging as exemplified in a recent negative result of a randomized controlled trial of a carefully designed course for residents in internal medicine. ${ }^{14}$ Performing clinical research in residency may increase critical appraisal skills, ${ }^{15,16}$ but insufficient time hinders research. ${ }^{17}$ Writing critically appraised topics (CATs) is easier than performing research. ${ }^{18}$ CATs begin with a clinical question, usually based on a specific patient encounter, then summarize the best clinical 
evidence. However, drawbacks to CATs include the difficulty in keeping them up-todate as new research emerges, and difficulties in sharing CATs across institutions. $^{19}$ A Catmaker can help create CATS $;{ }^{20}$ a CAT Crawler can help locate CATs $;{ }^{21}$ a network of CATs may help distribution; ${ }^{22}$ and new collaborative editing tools such as Wikis provide logical solutions to the distribution and maintaining currency of clinical knowledge gained from participating projects.

A simpler approach might involve the use of Wikis to teach components of evidence-based practice. While use of Wikis has been encouraged in medical education ${ }^{23-}$ 27 and teaching public policy, ${ }^{28}$ there appears to be no published research on the acceptance of their use for this purpose. This paper reports observations from the introduction of collaborative editing of Wikipedia into the curriculum of a senior medical school elective.

\section{Methods}

During March 2007 and 2008, senior medical students at the University of Texas Health Science Center at San Antonio chose an elective that was advertised as being for "students who want to master information".
The elective included 4 hours of classroom time for learning about Wikis and additional online instruction was available. For the 2008 class, an online template for edits was developed for student use.

Students were encouraged to make two edits in Wikipedia for a biomedical topic of their choice: One edit was to address the diagnosis while the second edit was to address treatment of their topic. The students were instructed to search for a representative original study for each edit with the goal of succinctly summarizing the type of study and its central finding. More specific instructions are summarized in Table 1.

At the end of the last session, the students were asked to complete an, anonymous survey (Table 2). The survey asked three questions about editing Wikipedia using a five-item Likert response and also asked for open ended comments. The pages and their histories at Wikipedia were reviewed systematically after two months for the criteria listed in Table 3.

The Institutional Review Board determined that this research did not involve human subjects and that Code of Federal Regulations (45 CFR 46) did not apply.

\section{Table 1. Instructions given to students.}

\section{Instructions given only in 2007}

- Succinctly summarize the type of study and its central finding in one sentence.

Instructions given only in $\mathbf{2 0 0 8}$

- Use the online template to help you design a short summary.

Instructions given both years

- Note the authorship of the study if by a well-recognized evidence-based group such as the Cochrane Collaboration or United States Preventive Service Task Force.

- Numerically represent the results if possible.

- Link concepts in their edit to more detailed pages at Wikipedia and elsewhere. For example, students were given a list of instructions on linking to Wikipedia pages about randomized controlled trials, sensitivity, and number needed to treat.

- Link the edit to the citation at PubMed.

- Place the edit in the relevant section of the resource they choose to edit.

- Avoid making a clinical recommendation unless they truly feel expert on a topic. 
Table 2. Anonymous survey at course end.

1. Should this exercise be repeated for next year's class?

2. Do you think you will make medical edits to a collaborative-edit system such as Wikipedia in the future?

3. Would you be more likely to make medical edits in the future if the interface for editing were easier to use?

The responses allowed for each question were:

Strongly disagree, Disagree, Neither agree nor disagree, Agree, Strongly agree

Table 3. Review of edits after two months.

Review of the original edits

a. A statement of a study design.

b. Numeracy by stating either sensitivity and specificity or a measure of risk reduction.

c. A hyperlink to the PubMed citation.

d. A complete citation according to Wikipedia standards.

e. A hyperlink to related content in the Wiki.

Review of the page history at two months

a. Changes or deletions of the original edits.

b. Changes to any part of the page containing the original edit to correct vandalism.

\section{Results}

Compliance with the assignment. All students complied with the assignment; however, one student in 2008 cited recommendations from UpToDate (a subscription-based clinical reference tool) rather than original research. In 2007, 21 students edited 23 pages. In 2008, 18 students edited 21 pages. One student in 2007 created a new Wikipedia page.

Content of edits. Combing the two years, all students but one (97\%) cited articles at PubMed. Most students (79\%) reported a study design and $72 \%$ provided numeric results (Table 4). Regarding hyperlinking edits to underlying sources, $85 \%$ of students created hyperlinks to abstracts at PubMed. In 2007, only 14\% created a formal citation, whereas $78 \%$ of students in 2007 created a formal citation (p
$<0.05)$. Most of the students $(79 \%)$ created additional hyperlinks to a relevant web page either within or outside of Wikipedia. Almost half $(44 \%)$ of students contributed their edits anonymously. Of the $56 \%$ of students registered at Wikipedia, none provided their real names.

An example of an exemplary edit from 2007, that is still present in 2011, is on the page "Bowel Obstruction":"

"According to a meta-analysis of prospective studies by the Cochrane Collaboration, the appearance of water-soluble contrast in the cecum on an abdominal radiograph within 24 hours of oral administration predicts resolution of an adhesive small bowel obstruction with a pooled sensitivity of $96 \%$ and specificity of $96 \%$."

* Available at: http://en.wikipedia.org/wiki/Bowel_obstruction.

** The edit can be viewed in isolation in the page history at Wikipedia: http://en.wikipedia.org/w/ index.php?title= Bowel_obstruction\&action=historysubmit\&diff $=119060338 \&$ oldid=117779804. 
An exemplary edit from 2008, which used the online template for the class to add an edit to the page "Cervical Cancer" and is present in 2011 after being moved to the page Cervical Screening: ${ }^{\dagger}$

"HPV testing can reduce the incidence of grade 2 or 3 cervical intraepithelial neoplasia or cervical cancer detected by subsequent screening tests among women 32-38 years old according to a randomized controlled trial. The relative risk reduction was $41.3 \%$. For patients at similar risk to those in this study (63.0\% had CIN 2-3 or cancer), this leads to an absolute risk reduction of 26\%. 3.8 patients must be treated for one to benefit (number needed to treat $=3.8)$."

Receptiveness survey at course end. In $2007,83 \%$ of students agreed or strongly agreed that the exercise should repeat next year (Table 4). Most (72\%) said they would be more likely to make future edits if editing was technically easier. In 2008, all respondents to the survey agreed or strongly agreed that the exercise should repeat the next year. Selected comments are in Table 5 .

Table 4. Results.

\begin{tabular}{|c|c|c|c|}
\hline & \multicolumn{2}{|c|}{ Year } & \multirow{2}{*}{ Combined } \\
\hline & 2007 & 2008 & \\
\hline & $\mathrm{N}=21$ & $\mathrm{~N}=18$ & $\mathrm{~N}=39$ \\
\hline Registered at Wikipedia & $52 \%$ & $61 \%$ & $56 \%$ \\
\hline \multicolumn{4}{|l|}{ Quality of edits } \\
\hline Study design stated & $76 \%$ & $83 \%$ & $79 \%$ \\
\hline Numeracy provided & $72 \%$ & $72 \%$ & $72 \%$ \\
\hline Hyperlink to PubMed abstract & $90 \%$ & $78 \%$ & $85 \%$ \\
\hline Complete citation & $14 \%$ & $78 \%{ }^{*}$ & \\
\hline Hyperlinks to other web pages & $76 \%$ & $83 \%$ & $79 \%$ \\
\hline \multicolumn{4}{|l|}{ Durability of edits at 2 months } \\
\hline Improved & $48 \%$ & $44 \%$ & $46 \%$ \\
\hline Hosting pages vandalized & $67 \%$ & $56 \%$ & $62 \%$ \\
\hline Receptiveness survey & $\mathrm{N}=18$ & $\mathrm{~N}=16$ & $\mathrm{~N}=34$ \\
\hline $\begin{array}{l}\text { Should the project continue } \\
\text { next year? }\end{array}$ & $83 \%$ & $100 \%$ & $91 \%$ \\
\hline Plan to do future edits? & $72 \%$ & $69 \%$ & $71 \%$ \\
\hline
\end{tabular}

\footnotetext{
${ }^{\dagger}$ Available at: http://en.wikipedia.org/wiki/Cervical_screening.

* This edit can be viewed in isolation in the page history (http://en.wikipedia.org/w/ index.php?title=Cervical_ cancer\&action=historysubmit\&diff=198849853\&oldid=197483778)
} 
Table 5. Selected comments.

2007

The following are 4 of the 9 comments. The last comment was the only negative comment received.

- "I think the current system is not very difficult, especially after seeing how to do it in class. Without this project, I might never have tried to edit Wikipedia. Now, I think that when I look up the answer to something, I might just throw the answer up for others who wonder the same thing."

- "Learning how to edit Wikipedia was a fun exercise, I don't know if I will do it again in the future."

- "Have used Wikipedia before, but did not realize that that the general public can write info in it."

- "I was forced into this course by the registars [sic] office. I hope the next class will not have to take this course. It did not help me."

\section{8}

The following are 3 of the 13 comments. There were no negative comments.

- "The actual editing of a Wiki page is not necessarily something I would do in the future, but the process of learning how to do good research and cite articles for evidence-based documents was very helpful."

- "The Wiki edit was useful and I think I will look at the medical edits in the future because of this class."

- "This was a good learning experience....never knew how Wiki worked before."

Status of edits at two months. At twomonths follow-up, $46 \%$ of students had at least one edit improved and one edit from 2007 was deleted (Table 2). After the original edits were completed, one improvement occurred within three minutes and one within four hours. One student who completed her edits over several days had one of her earlier edits improved upon amid her work. Most of the improvements were corrections of typographical errors and improvements in formatting. Some of these edits were made by automated bots at Wikipedia (http://en.wikipedia.org/wiki/ Wikipedia:Bots). One improvement was added by the original student and is the only instance of a student returning to Wikipedia after the course ended. The pages edited by $62 \%$ of students had additional edits in response to incidental vandalism to the pages, but in no instance was the vandalism done to an edit by a student.

\section{Discussion}

This study showed that a selected group of senior medical students can make short edits to Wikipedia and are sufficiently receptive to the assignment to recommend the assignment be repeated the next academic year. The provision of an online template may have helped the technical quality of the edits. 
This participatory method of learning is consistent with active learning ${ }^{29}$ as opposed to learning via lecture and rote memorization. $^{30}$ Our assignment is similar to collaborative writing of a letter to the editor. $^{31}$

Although this project focused on learning evidence based practice rather than how to contribute to Wikis, some students may benefit from learning how to edit Wikis because of their future work. Students who become clinical informationists may edit Wikis as hospitals are starting to use Web 2.0 methods such as Wikis to codify their institutional knowledge. ${ }^{32}$ Students who become researchers may edit Wikis as a way to share knowledge for team science. ${ }^{33-36}$

There are limitations to this study. First, this was an uncontrolled study in a small group of selected senior medical students. Second, this study did not measure whether the students actually learned evidence-based practice or altered their learning habits. Third, this project did not have the resources to examine formally whether the edits correctly summarized the article. Accuracy was sought by encouraging the students to work in pairs and having a faculty internist review each edit. We note that ensuring correctness is a limitation of any

\section{References}

${ }^{1}$ Bergman DA, Pantell RH. The impact of reading a clinical study on treatment decisions of physicians and residents. $\mathbf{J}$ Med Educ 1986; 61(5):380-386. PMID: 3701813.

2 Cohen SJ, Weinberger M, Hui SL, Tierney WM, McDonald CJ. The impact of reading on physicians' nonadherence to recommended standards of medical care. Soc Sci Med 1985; 21(8):909-914. PMID: 4071124.

${ }^{3}$ Gross CP, Steiner CA, Bass EB, Powe NR. Relation between prepublication release of clinical trial results and the practice of participatory learning. In comparison to CATs, however, Wikis can be corrected and maintained much easier. Lastly, the optimal structure of a medical edit is not known. For example, should the edit state the study design or is a link to the abstract adequate?

This study showed that teaching components of evidence-based practice with collaborative editing is feasible in limited group of self-selected medical students. Further study is needed in a broader group of students. In addition, research can be conducted in other Wikis that may emerge and become more scholarly than Wikipedia. If a broader group of students is receptive, then research can address whether editing a Wiki improves the knowledge, skills, and behavior of medical students regarding evidence based medicine.

"A doctor who accesses the world wide web ... to seek the answer to a question but does not find it there and has the facility to place material on the web ... must place that answer on the web where the next one to ask the same question can find it". 37

\section{Acknowledgments}

Classroom space and time generously was provided by the Briscoe Library.

carotid endarterectomy. JAMA 2000; 284 (22):2886-2893. PMID: 11147985.

4 Berwick DM, Fineberg HV, Weinstein MC. When doctors meet numbers. Am J Med 1981; 71(6):991-998. PMID: 7315859.

5 Steinberg EP, Dans PE, Keruly JC, Egbuonu LC. A case study of physicians' use of liver-spleen scans. Are we doing what we think we're doing? Arch Intern Med 1986; 146(2):253-258. PMID: 3947184.

${ }^{6}$ Bucher HC, Weinbacher M, Gyr K. Influence of method of reporting study 
results on decision of physicians to prescribe drugs to lower cholesterol concentration. BMJ 1994; 309(6957):761764. PMID: 7950558.

7 De Smet BD, Fendrick AM, Stevenson JG, Bernstein SJ. Over and under-utilization of cyclooxygenase-2 selective inhibitors by primary care physicians and specialists: The tortoise and the hare revisited. J Gen Intern Med 2006; 21(7):694-697. PMID: 16808768.

${ }^{8}$ Bozkurt B, Agoston I, Knowlton AA. Complications of inappropriate use of spironolactone in heart failure: When an old medicine spirals out of new guidelines. J Am Coll Cardiol 2003; 41(2):211-214. PMID: 12535810.

${ }^{9}$ Win HK, Caldera AE, Maresh $\mathrm{K}$, et al. Clinical outcomes and stent thrombosis following off-label use of drug-eluting stents. JAMA 2007; 297(18):2001-2009. PMID: 17488965.

${ }^{10}$ Juurlink DN, Mamdani MM, Lee DS, et al. Rates of hyperkalemia after publication of the Randomized Aldactone Evaluation Study. N Engl J Med 2004; 351(6):543-551. PMID: 15295047.

${ }^{11}$ Shah KB, Rao K, Sawyer R, Gottlieb SS. The adequacy of laboratory monitoring in patients treated with spironolactone for congestive heart failure. J Am Coll Cardiol 2005; 46(5):845-849. PMID: 16139135.

${ }^{12}$ McKibbon KA, Fridsma DB. Effectiveness of clinician-selected electronic information resources for answering primary care physicians' information needs. J Am Med Inform Assoc 2006; 13(6):653-659. PMID: 16929042.

${ }^{13}$ Mulrow CD. Rationale for systematic reviews. BMJ 1994; 309(6954):597-599. PMID: 8086953.

${ }^{14}$ Feldstein DA, Maenner MJ, Srisurichan R, Roach MA, Vogelman BS. Evidencebased medicine training during residency:
A randomized controlled trial of efficacy. BMC Med Educ 2010; 10:59. PMID: 20807453.

${ }^{15}$ Hebert RS, Levine RB, Smith CG, Wright SM. A systematic review of resident research curricula. Acad Med 2003; 78(1):61-68. PMID 12525411.

${ }^{16}$ Hayward R, Taweel F. Data and the internal medicine houseofficer: Alumni's views of the educational value of a residency program's research requirement. J Gen Intern Med 1993; 8(3):140-142. PMID: 8455110.

${ }^{17}$ Rivera JA, Levine RB, Wright SM. Completing a scholarly project during residency training. Perspectives of residents who have been successful. J Gen Intern Med 2005; 20(4):366-369. PMID: 15857496.

${ }^{18}$ Sauve S, Lee HN, Meade MO, et al. The critically-appraised topic (CAT): A resident-initiated tactic for applying users' guides at the bedside. Ann R Coll Physicians Surg Can 1995; 28:396-398.

${ }^{19}$ Ismach RB. Teaching evidence-based medicine to medical students. Acad Emerg Med 2004; 11(12):e6-10. PMID: 15579428.

${ }^{20}$ Centre for Evidence-based Medicine. CATmaker. Accessed at: http:// www.cebm.net/index.aspx?o=1216.

${ }^{21}$ Dong P, Wong LL, Ng S, Loh M, Mondry A. Quantitative evaluation of recall and precision of CAT crawler, a search engine specialized on retrieval of Critically Appraised Topics. BMC Med Inform Decis Mak 2004; 4(1):21. PMID: 15588311.

${ }^{22}$ Castro J, Wolf F, Karras B, Tolentino H, Marcelo A, Maramba I. Critically Appraised Topics (CAT) peer-to-peer network. AMIA Annu Symp Proc 2003:806. PMID: 14728311.

${ }^{23}$ Sandars J. Social software and digital competences. InnovAiT 2010; 3(5):306309. 
${ }^{24}$ Sandars J, Homer M, Pell G, Crocker T. Web 2.0 and social software: The medical student way of e-learning. Med Teach 2010; Jun 18. PMID: 20560756.

${ }^{25}$ Sandars J. Twelve tips for using blogs and wikis in medical education. Med Teach 2006; 28(8):680-682. PMID: 17594577.

${ }^{26}$ McGee JB, Begg M. What medical educators need to know about "web 2.0". Med Teach 2008; 30(2):164-169. PMID: 18464141.

${ }^{27}$ Boulos MN, Maramba I, Wheeler S. Wikis, blogs and podcasts: A new generation of Web-based tools for virtual collaborative clinical practice and education. BMC Med Educ 2006; 6:41. PMID: 16911779.

${ }^{28}$ Schulenburg F. Wikipedia heads to school. San Francisco, CA: Wikimedia Foundation, 2010. Accessed at: http://blog.wikimedia.org/blog/2010/05/11 /wikipedia-heads-to-school/.

${ }^{29}$ Cuseo J, McLaughlin J, Thompson, A, Moono S. Thriving in the Community College AND Beyond: Strategies for Academic Success and Personal Development. Dubuque, IA: Kendall Hunt Publishing, 2010. ISBN: 978-07575-7283-8.

${ }^{30}$ Regan-Smith MG, Obenshain SS, Woodward C, Richards B, Zeitz HJ, Small PA Jr. Rote learning in medical school. JAMA 1994; 272(17):1380-1381. PMID: 7933403.
${ }^{31}$ Kallen AJ, Wilson CT, Russell MA, et al. Group writing of letters to the editor as the goal of journal club. JAMA 2006; 296(9):1053-1054. PMID: 16954483.

${ }^{32}$ Wright A, Bates DW, Middleton B, et al. Creating and sharing clinical decision support content with Web 2.0: Issues and examples. J Biomed Inform 2009; 42(2):334-346. PMID: 18935982.

${ }^{33}$ Zerhouni EA. US biomedical research: Basic, translational, and clinical sciences. JAMA 2005; 294(11):1352-1358. PMID: 16174693.

${ }^{34}$ Heinig SJ, Krakower JY, Dickler HB, Korn D. Sustaining the engine of U.S. biomedical discovery. $\mathrm{N}$ Engl J Med 2007; 357(10):1042-1047. PMID: 17804852.

${ }^{35}$ Cohen JJ, Siegel EK. Academic medical centers and medical research: The challenges ahead. JAMA 2005; 294(11):1367-1372. PMID: 16174695.

${ }^{36}$ Lorenzi NM, Novak LL, Weiss JB, Gadd CS, Unertl KM. Crossing the implementation chasm: A proposal for bold action. J Am Med Inform Assoc 2008; 15(3):290-296. PMID: 18308985.

${ }^{37}$ Midgley A. Global medical knowledge database. New professional obligation arises. BMJ 2000; 321(7245):1340. PMID: 11039986.

Keywords: evidence based practice, medical education, medical informatics 